\title{
SLCO1B1*5 polymorphism (rs4149056) is associated with chemotherapy-induced amenorrhea in premenopausal women with breast cancer: a prospective cohort study
}

Toralf Reimer $^{1 *}$, Sarah Kempert ${ }^{1}$, Bernd Gerber ${ }^{1}$, Hans-Jürgen Thiesen², Steffi Hartmann ${ }^{1}$ and Dirk Koczan ${ }^{2}$

\begin{abstract}
Background: Because inheritance is recognized as playing a role in age at menarche and natural menopause, the development of chemotherapy-induced amenorrhea (CIA) might depend on inherited genetic factors; however, studies that explore such a correlation are few and have received scant attention. Given the importance of this topic we conducted a comprehensive genotype study in young women ( $\leq 45$ years) with early-stage breast cancer.

Methods: Our approach tested the effect of variant polymorphisms in drug metabolism enzymes (DMEs) using a predesigned pharmacogenomics panel (TaqMan ${ }^{\circledR}$ OpenArray ${ }^{\circledR}$, Life Technologies $\mathrm{GmbH}$, Darmstadt, Germany) in premenopausal women $(n=50)$. Patients received contemporary chemotherapy; in all cases a cyclophosphamide-based regimen with a dose of at least $500 \mathrm{mg} / \mathrm{m}^{2}$ for six cycles. CIA was considered to be present in women with no resumption of menstrual bleeding within 12 months after completion of chemotherapy or goserelin.

Results: Twenty-six patients (52\%) showed CIA during follow-up whereas 24 women (48 \%) remained premenopausal. Of all the DMEs studied, only the SLCO1B1*5 (rs4149056) genotype was associated with the development of CIA ( $P=0.017)$. Of the 26 patients who were homozygous for the T/T allele SLCO1B1*5, $18(69.2 \%)$ developed CIA compared with 8 (30.8\%) of the 22 patients who were heterozygous (C/T allele). The association of heterozygous SLCO1B1*5 allele (OR 0.038; 95\%Cl: 0.05-0.92) with a lower risk of developing CIA remained significant in a binary logistic regression analysis that include age, SLCO1B1*5 allele variants, and goserelin therapy. Conclusions: Patient age and SLCO1B1*5 allele variants predict the likelihood of young women with breast cancer developing CIA.
\end{abstract}

Keywords: Breast cancer, Chemotherapy-induced amenorrhea, OpenArray genotyping, Single nucleotide polymorphism, SLCO1B1

\footnotetext{
* Correspondence: toralf.reimer@med.uni-rostock.de

1 Department of Obstetrics and Gynecology, University of Rostock, Klinikum

Suedstadt, Suedring 81, Rostock 18059, Germany

Full list of author information is available at the end of the article
} 


\section{Background}

In Germany, $10 \%$ of all newly diagnosed breast cancers are detected in the age group under 45 years old [1]. Patients younger than 50 years of age, especially those with hormone-insensitive breast cancer, achieve significant benefit from adjuvant systemic chemotherapy in terms of prolonged disease-free and overall survival [2]. However, a considerable number of these young patients will suffer from chemotherapy-induced amenorrhea (CIA) thereafter, depending on age at diagnosis and type of chemotherapy used [3].

Premenopausal women in whom amenorrhea developed as a consequence of adjuvant breast cancer therapy had significantly better disease-free and overall survival than did women without amenorrhea, particularly when the tumor was estrogen receptor (ER)-positive [4]. Interestingly, the dose of the chemotherapy drug delivered was not a key factor in accounting for these differences [5]. Apart from its impact on survival and the loss of fertility, CIA due to premature ovarian failure leads to subjective and objective menopausal symptoms, which can negatively affect short- and long-term quality of life [6, 7].

Apart from its relationship with patient age at the time of therapy, there are no proven patient characteristics that are predictive of CIA [3, 8]. Pretreatment antiMüllerian hormone (AMH), a biomarker of ovarian reserve, appears to be a potential predictor of CIA in women with early breast cancer [9]. However, further studies are needed in order to define the regimenspecific action of chemotherapy on AMH levels, the percentage of post-treatment recovery of $\mathrm{AMH}$ levels, and the relationship between menopausal status and $\mathrm{AMH}$ [10]. Because inheritance is recognized as playing a role in age at menarche and natural menopause $[11,12]$, the development of CIA might also depend on inherited genetic factors; however, studies that explore such a correlation are few and have received scant attention [13].

Previous pharmacogenetic investigations on CIA have focused on alkylating-based regimens. Cyclophosphamide is a pro-drug that requires activation by multiple cytochrome P450 (CYP450) enzymes [14]. The effect of cyclophosphamide on ovarian toxicity in patients with systemic lupus erythematosus has been found to be associated with the CYP2C19 genotype [15-17]. In another study women with CYP3A*1B variant genotype demonstrated a higher risk of ovarian failure after cyclophosphamide-based chemotherapy [18]. In conflict with these data, a pilot study investigating six CYP450 genotypes $(n=20)$ did not reveal a genetic effect on CIA in women with breast cancer receiving anthracyclineand cyclophosphamide-based therapy [19].

Solute carrier (SLC) transporters mediate the influx of cytotoxic drugs into cells. Organic anion-transporting polypeptides (OATPs) encoded by the solute carrier organic anion (SLCO) genes constitute an important transporter superfamily that mediates transmembrane transport of various clinical drugs and endogenous nutrients. Eleven human OATPs with different transport functions are expressed in various tissues. Many important clinical drugs have been identified as substrates of liver-specific OATP1B1 and OATP1B3 [20, 21].

SLCO1B1 encodes the organic anion-transporting polypeptide OATP1B1, which mediates the hepatic uptake of various drugs [22]. Previous studies have shown associations between genetic polymorphisms in SLCO genes and the uptake pharmacokinetics of their substrates. A common single-nucleotide variation (coding DNA c.521 T $>$, protein p.V174A, rs4149056) in the SLCO1B1 gene decreases the transporting activity of OATP1B1, resulting in markedly increased plasma concentrations of many statins, for example [23].

Given the importance of this topic we planned a more comprehensive genotype study in a larger cohort of young women with early breast cancer. Our approach tested the effect of variant polymorphisms in drug metabolism enzymes (DMEs) using a predesigned pharmacogenomics panel in premenopausal women receiving contemporary chemotherapy.

\section{Methods \\ Patients}

A total of 50 premenopausal patients diagnosed with earlystage breast cancer between July 2001 and January 2011 were included in this prospective cohort analysis. All patients were aged $\leq 45$ years at the time of diagnosis and were suitable to receive pre- or postoperative chemotherapy. In all cases patients received a cyclophosphamidebased regimen with a defined dose of at least $500 \mathrm{mg} / \mathrm{m}^{2}$ of body surface area for six cycles. Details of the protocols used in terms of administration of anthracyclines and/or taxanes are listed in Table 1.

Only $30 \% \quad(n=15)$ of all cases had hormoneinsensitive breast cancer. Women with hormone receptor-positive disease $(n=35)$ received tamoxifen in a dosage of $20 \mathrm{mg}$ daily for 5 years. Additionally, $50 \%$ ( $n$ $=25$ ) of included patients were treated with the gonadotrophin-releasing hormone (GnRH) agonist goserelin, $3.6 \mathrm{mg}$ subcutaneously every 4 weeks, in two different clinical situations: 1) concurrent treatment with chemotherapy in hormone-insensitive breast cancer according to the ZOladex Rescue of Ovarian function (ZORO) study protocol $(n=4)$ [24]; or 2 ) concurrent and/or sequential goserelin application for a maximum of 2 years in hormone receptor-positive disease $(n=21)$.

\section{Clinical outcomes}

At enrollment before chemotherapy, all women were premenopausal as defined by regularly occuring menstrual 
Table 1 Summary of regimens used for pre- or postoperative chemotherapy in premenopausal women with early-stage breast cancer $(n=50)$

\begin{tabular}{|c|c|c|c|c|c|c|}
\hline \multirow[t]{2}{*}{ Regimen } & \multirow{2}{*}{$\begin{array}{l}\text { Patients } \\
\mathrm{n}(\%)\end{array}$} & \multirow[t]{2}{*}{ Cycles } & \multirow{2}{*}{$\begin{array}{l}\text { Interval } \\
\text { (weeks) }\end{array}$} & \multicolumn{3}{|l|}{ Dose per cycle } \\
\hline & & & & Cyclophosphamide & Anthracycline & Docetaxel \\
\hline$\overline{T A C}$ & $23(46 \%)$ & 6 & 3 & $500 \mathrm{mg} / \mathrm{m}^{2}$ & $50 \mathrm{mg} / \mathrm{m}^{2}(\mathrm{~A})$ & $75 \mathrm{mg} / \mathrm{m}^{2}$ \\
\hline FEC & $15(30 \%)$ & 6 & 3 & $500 \mathrm{mg} / \mathrm{m}^{2}$ & $90 \mathrm{mg} / \mathrm{m}^{2}(\mathrm{E})$ & - \\
\hline $\mathrm{TC}$ & $8(16 \%)$ & 6 & 3 & $600 \mathrm{mg} / \mathrm{m}^{2}$ & - & $75 \mathrm{mg} / \mathrm{m}^{2}$ \\
\hline EC & $2(4 \%)$ & 6 & 3 & $600 \mathrm{mg} / \mathrm{m}^{2}$ & 90 mg/m² (E) & - \\
\hline FAC & $1(2 \%)$ & 6 & 3 & $500 \mathrm{mg} / \mathrm{m}^{2}$ & $50 \mathrm{mg} / \mathrm{m}^{2}(\mathrm{~A})$ & - \\
\hline$A C$ & $1(2 \%)$ & 6 & 3 & $600 \mathrm{mg} / \mathrm{m}^{2}$ & $60 \mathrm{mg} / \mathrm{m}^{2}(\mathrm{~A})$ & - \\
\hline
\end{tabular}

$T$ Taxotere $^{\oplus}$ (docetaxel), $A$ adriamycin (doxorubicin), $C$ cyclophosphamide, $F$ fluorouracil, $E$ epirubicin

cycles. Follow-up assessment of menopausal status was performed 12 months after chemotherapy completion or 12 months from discontinuation of goserelin treatment. Normal ovarian function was defined as two consecutive menstrual periods within 21 to 35 days in a timeframe of 5 to 8 months after last administration of chemotherapy or goserelin. CIA was considered to be present in women with no resumption of menstrual bleeding within 12 months after completion of chemotherapy or goserelin. Plasma levels of follicle-stimulating hormone (FSH) and estradiol (E2) were measured during follow-up for serologic definition of menopausal status.

\section{DNA extraction and DME genotyping}

Venous blood samples were taken prior to chemotherapy using PAXgene Blood DNA tubes (Qiagen, Hilden, Germany). DNA was purified according to the manufacturer's instructions for the PAXgene Blood DNA kit (Qiagen) in a single-tube procedure. The homogenization of lysates was optimized by biopolymer-shredding system (QIAshredder, Qiagen). Extracted DNA was assessed with a micro-volume spectrophotometer (NanoDrop 8000, Fisher Scientific GmbH, Schwerte, Germany) and by analysis of housekeeping gene expression using conventional polymerase chain reaction (PCR). Additional DNA quantification was performed using Quant-iT ${ }^{\mathrm{TM}}$ DNA Assay kit (Invitrogen, Carlsbad, CA, USA), resulting in an optimal DNA concentration of $50 \mathrm{ng} / \mu \mathrm{L}$.

The TaqMan ${ }^{\circledR}$ OpenArray ${ }^{\odot}$ Pharmacogenomics (PGx) Panel (Life Technologies GmbH, Darmstadt, Germany) was used for genotyping analysis of DMEs and associated transport proteins. This OpenArray ${ }^{\circ}$ genotyping plate includes assays for preformatted targets on a 192well format (16 samples per panel; 3 sub-arrays per sample). Each TaqMan ${ }^{\oplus}$ DME Genotyping Assay contains two allele-specific probes and a primer pair to detect the specific SNP target. A total of 29 genes are covered across 164 unique assays (gene list available in Additional file 1: Table S1). Data were analyzed with OpenArray ${ }^{\circ}$ SNP Genotyping Analysis software and then imported into TaqMan ${ }^{\odot}$ Genotyper $^{\mathrm{TM}}$ software. $^{-}$

\section{Statistical analysis}

The Chi-squared test and Fisher's exact test were used to compare categorical variables. The Mann-Whitney $U$ test was performed to compare continuous variables, and Spearman's correlation coefficient is given, where appropriate. Binary logistic regression was performed to analyze the impact of factors predictive of CIA. Diseasefree survival was analyzed using Kaplan-Meier method, with the log-rank test for comparison of subgroups. All analyses were conducted with the IBM SPSS Statistics Package, version 20 (IBM Deutschland GmbH, Ehningen, Germany). In all tests $P<0.05$ was considered statistically significant, and all $P$-values cited were from two-tailed tests.

We performed post hoc analysis to estimate the statistical power of the described logistic regression analysis using the G*Power 3.1.9.2 tool [25]. Two-tailed analysis for prediction of CIA by the rs4149056 polymorphism with an $\alpha$ error of 0.05 revealed a statistical power of $70 \%$ for our sample size.

\section{Results}

Fifty subjects with complete data sets were included in this analysis. Twenty-six patients (52 \%) showed CIA during follow-up whereas 24 women (48 \%) remained premenopausal throughout the study. Among CIA subgroup $(n=26)$, serologic FSH and E2 assessment after completion of chemotherapy or goserelin confirmed peri- or postmenopausal status in the majority of cases: 15 postmenopausal (57.7\%), 8 perimenopausal (30.8\%), and 3 premenopausal (11.5\%). Table 2 shows the demographic and tumor characteristics for both subgroups (remained premenopausal vs. CIA). The only significant differences between the two groups were age $(P=0.001)$ and total duration of menstruation $(P=0.005)$. As expected, women who experienced CIA were significantly older than those who did not.

On analyzing the 164 assays of the PGx panel with respect to CIA, no statistics were computed for 89 assays $(54.3 \%)$ because results of these targets were constant, and 23 further assays (14 \%) were excluded from the 
Table 2 Demographic and tumor characteristics of study population (Caucasian women, $n=50$ )

\begin{tabular}{|c|c|c|c|}
\hline & $\begin{array}{l}\text { Remained premenopausal } \\
(n=24)\end{array}$ & $\begin{array}{l}\mathrm{CIA} \\
(n=26)\end{array}$ & $P$-value \\
\hline Mean age in years ( \pm SD) & $36.7(4.8)$ & $41.1(4.0)$ & 0.001 \\
\hline Mean BMI kg/m² $( \pm S D)$ & $22.6(2.9)$ & $23.8(3.8)$ & 0.38 \\
\hline \multicolumn{3}{|l|}{ Smoking:* } & 1.0 \\
\hline No & 20 & 20 & \\
\hline Yes & 4 & 4 & \\
\hline $\begin{array}{l}\text { Mean age in years } \\
\text { at menarche }( \pm S D)\end{array}$ & $13.1(0.9)$ & $12.8(1.2)$ & 0.44 \\
\hline $\begin{array}{l}\text { Mean total duration } \\
\text { of menstruation in } \\
\text { years }( \pm S D)\end{array}$ & $23.4(5.1)$ & $28.1(4.8)$ & 0.005 \\
\hline Mean parity $( \pm S D)$ & $1.4(0.9)$ & $1.7(1.0)$ & 0.49 \\
\hline \multicolumn{3}{|l|}{ Tumor stage: } & 0.21 \\
\hline pT1 & 14 & 18 & \\
\hline pT2 & 7 & 8 & \\
\hline pT3 \& pT4 & 3 & 0 & \\
\hline \multicolumn{3}{|l|}{ Nodal stage: } & 0.82 \\
\hline pNO & 11 & 11 & \\
\hline pN1 & 9 & 8 & \\
\hline $\mathrm{pN} 2 \& \mathrm{pN} 3$ & 4 & 7 & \\
\hline \multicolumn{3}{|l|}{ Tumor grading:* } & 0.23 \\
\hline 1 & 3 & 0 & \\
\hline 2 & 10 & 12 & \\
\hline 3 & 10 & 14 & \\
\hline \multicolumn{3}{|l|}{ Estrogen receptor status: } & 0.55 \\
\hline Positive & 15 & 19 & \\
\hline Negative & 9 & 7 & \\
\hline \multicolumn{3}{|c|}{ Progesterone receptor status: } & 0.77 \\
\hline Positive & 16 & 16 & \\
\hline Negative & 8 & 10 & \\
\hline \multicolumn{3}{|l|}{ HER2 status: } & 1.0 \\
\hline Positive & 4 & 4 & \\
\hline Negative & 20 & 22 & \\
\hline \multicolumn{3}{|l|}{ Tamoxifen therapy: } & 0.77 \\
\hline Yes & 14 & 17 & \\
\hline No & 10 & 9 & \\
\hline \multicolumn{3}{|l|}{ Goserelin therapy: } & 0.11 \\
\hline No & 9 & 16 & \\
\hline $\begin{array}{l}\text { Concurrent to } \\
\text { chemotherapy }\end{array}$ & 7 & 2 & \\
\hline $\begin{array}{l}\text { Sequential to } \\
\text { chemotherapy }\end{array}$ & 8 & 8 & \\
\hline \multicolumn{3}{|l|}{ Taxan-based chemotherapy: } & 0.77 \\
\hline Yes & 14 & 17 & \\
\hline No & 10 & 9 & \\
\hline
\end{tabular}

* denotes missing values analysis because their frequencies were not in HardyWeinberg equilibrium. The remained 52 assays of interest were assessed for data quality, resulting in 34 finally evaluated assays (20.7 \%) with complete and reproducible data sets (Additional file 2: Table S2, Additional file 3: Table S3).

Of all the DMEs studied, only the genotype of SLCO1B1*5 (rs4149056) was associated with the development of CIA $(P=0.017)$. Of the 26 patients who were homozygous for the SLCO1B1*5 T/T allele, 18 (69.2\%) developed CIA, compared with 8 (33.3 \%) of the 24 patients who were either heterozygous or homozygous for the $\mathrm{C}$ allele (Table 3). SLCO1B1*5 genotype allele distribution as a function of chemotherapeutic regimen and patient age group is presented in Tables 4 and 5 . The correlation between rs4149056 polymorphism and CIA was significant (Spearman $\mathrm{r}_{\mathrm{s}}=0.378, P=0.007$ ).

Furthermore, the association of heterozygous SLCO1B1*5 allele with a lower risk of developing CIA remained significant on binary logistic regression analysis that include factors with a $P$-value $<0.2$ in the univariate setting: age groups, SLCO1B1*5 allele variants, and goserelin therapy (Table 6). The protective effect of heterozygous SLCO1B1*5 allele regarding occurrence of CIA (odds ratio 0.22; $95 \%$ CI 0.05-0.92) appears to be unrelated to patient age at initiation of chemotherapy. Regression analysis revealed that age (odds ratio for $\geq 40$ years: 5.44 ; $95 \%$ CI $1.29-22.9)$ contributed significantly to the model, indicating that age and SLCO1B1*5 allele variants predict the likelihood of developing CIA.

Among this premenopausal study cohort, a recurrence of breast cancer was detected in 10 cases $(20 \%)$ during a median follow-up of 61 months (range 18-120 months). Disease-free survival was not related to occurrence of CIA (log-rank test, $P=0.526)$, SLCO1B1*5 genotype $(P=0.793)$, or age group $(P=0.985)$ using Kaplan-Meier method.

\section{Discussion}

CIA is relevant because $25 \%$ of women diagnosed with breast cancer are premenopausal, and previous studies suggest that CIA may impact breast cancer survival and patient's quality of life due to premature ovarian failure with associated infertility and menopausal symptoms in women younger than 50 years.

Currently, little is known about the genetics of chemotherapy-induced ovarian failure and CIA. It is possible that the same genetic changes that are associated with premature menopause might also predict treatment-induced menopause [13]. A second category of candidate genes might be those that are implicated in drug metabolism. These include transporters involved in absorption and distribution, and in renal or hepatic elimination, and enzymes of drug metabolism that are 
Table 3 SLCO1B1*5 genotype allele distribution as a function of resumption of menstrual bleeding $(n=50)$

\begin{tabular}{llll}
\hline $\begin{array}{l}\text { SLCO1B1*5 } \\
(\mathrm{rs} 4149056)\end{array}$ & $\begin{array}{l}\text { Remained premenopausal } \\
(n=24)\end{array}$ & $\begin{array}{l}\text { CIA } \\
(n=26)\end{array}$ & P-value \\
\hline $\mathrm{T} / \mathrm{T}(n=26)$ & $8(33.3 \%)$ & $\begin{array}{l}18 \\
(69.2 \%)\end{array}$ & 0.017 \\
$\mathrm{C} / \mathrm{T}(n=22)$ & $14(58.3 \%)$ & $8(30.8 \%)$ & \\
$\mathrm{C} / \mathrm{C}(n=2)$ & $2(8.4 \%)$ & 0 & \\
\hline
\end{tabular}

usually present in the liver or gastrointestinal tract. SNPs in drug transporters, metabolizing enzymes and drug targets have the potential to affect therapeutic efficacy and toxicity $[26,27]$.

Our study results are a further example of the importance of variant polymorphisms predicting toxicities from chemotherapy in breast cancer patients. Using a pharmacogenomic approach permitting rapid scan of multiple markers, a significant association with CIA in Causasian women was found only for the SLCO1B1*5 allele distribution (rs4149056) (Table 6). In particular, patients who have the homozygous $(\mathrm{T} / \mathrm{T})$ genotype of the rs4149056 polymorphism showed a higher risk for developing CIA compared with patients who have the homozygous $(\mathrm{C} / \mathrm{C})$ or heterozygous $(\mathrm{C} / \mathrm{T})$ genotype.

In a genome-wide study the SEARCH Collaborative Group has identified the rs4149056 C allele in SLCO1B1 as being strongly associated with an increased risk of statin-induced myopathy [28]. No SNPs in any other region were clearly associated with myopathy. Several clinical studies in the past have investigated associations between rs4149056 SLCO1B1 genotypes and statin pharmacokinetics [22]. Although not all yielded significant results, the collective evidence indicates that statin blood concentrations are higher in people with the $\mathrm{C}$ allele [28].

Substrates for OATP1B1 include anticancer agents like methotrexate [29], gimatecan, SN-38 (the active metabolite of irinotecan), and pazopanib [23]. Certain SLCO1B1 variants associated with enhanced clearance of methotrexate increase the risk of gastrointestinal toxicity when this compound is used to treat children with acute lymphoblastic leukemia [30].

Endogenous substrates of SLCO1B1 include steroid hormone conjugates such as estradiol-17 $\beta$-glucuronide

Table 4 SLCO1B1*5 genotype allele distribution as a function of chemotherapeutic regimen $(n=50)$

\begin{tabular}{llllllll}
\hline rs4149056 & TAC & FEC & TC & EC & FAC & AC & $P$-value \\
& $(n=23)$ & $(n=15)$ & $(n=8)$ & $(n=2)$ & $(n=1)$ & $(n=1)$ & \\
\hline $\mathrm{T} / \mathrm{T}$ & 12 & 9 & 4 & 0 & 0 & 1 & 0.714 \\
$\mathrm{C} / \mathrm{T}$ & 10 & 6 & 3 & 2 & 1 & 0 & \\
$\mathrm{C} / \mathrm{C}$ & 1 & 0 & 1 & 0 & 0 & 0 & \\
\hline
\end{tabular}

$T$ Taxotere $^{\oplus}$ (docetaxel), $A$ adriamycin (doxorubicin), $C$ cyclophosphamide, $F$ fluorouracil, $E$ epirubicin
Table 5 SLCO1B1*5 genotype allele distribution as a function of patient age group $(n=50)$

\begin{tabular}{llllll}
\hline rs4149056 & $\begin{array}{l}<5 \text { years } \\
(n=10)\end{array}$ & $\begin{array}{l}35-39 \text { years } \\
(n=13)\end{array}$ & $\begin{array}{l}40-44 \text { years } \\
(n=20)\end{array}$ & $\begin{array}{l}>44 \text { years } \\
(n=7)\end{array}$ & $P$-value \\
\hline $\mathrm{T} / \mathrm{T}$ & 5 & 6 & 11 & 4 & 0.703 \\
$\mathrm{C} / \mathrm{T}$ & 5 & 7 & 8 & 2 & \\
$\mathrm{C} / \mathrm{C}$ & 0 & 0 & 1 & 1 & \\
\hline
\end{tabular}

and estrone-3-sulfate [31]. In a nested case-control study in the California Teachers Study cohort, only genetic variation in SLCO1B1 was associated with breast cancer risk. There was also an indication that estrogenprogestin therapy (EPT) may interact with SNPs in SLCO1B1; one variant (rs4149013) was significantly associated with breast cancer risk in EPT users [32].

Furthermore, given the frequent occurrence of overlapping substrate specificities - and the fact that functionally important coding-region SNPs in genes encoding members of some transporters families may not be common - it might be most fruitful to focus on combinations of coding-region SNPs in genes encoding transporters that work in parallel or in series [33]. In our data (Additional file 4: Table S4), alongside the described significant SLCO1B1*5 polymorphism in relation to CIA, there was a trend for a second SLC transporter genotype (SLC15A2: rs2257212, rs2293616) to be associated with menopausal status after completion of chemotherapy $(P=0.093)$.

In addition to the novel described potential genetic risk factor (SNP rs4149056) for CIA, increased age is unequivocally associated with higher rates of CIA. Older women, often defined as those at least 40 years old, are more sensitive to chemotherapy-related ovarian ablation [3]. This can be attributed to the decreasing number of active ovarian follicles with increasing age [34]. Taking the cut-off of 40 years, we found significantly different incidences of CIA in the age group $<40$ years $(30.4 \%)$ compared with the subgroup $\geq 40$ years $(70.4 \%)$ when using contemporary chemotherapeutic regimens. Recently, the pharmacogenetic pilot study by Wessels et al. [19] including common variant alleles for CYP450 enzymes found no differences in genotype frequencies but,

Table 6 Binary logistic regression for prediction of CIA: SLCO1B1*5 allele distribution and goserelin therapy as co-variates adjusted for age

\begin{tabular}{lcll}
\hline Co-variates & $P$-value & Odds ratio & $95 \% \mathrm{Cl}$ \\
\hline age $(<40$ vs. $\geq 40$ years $)$ & 0.021 & 5.44 & $1.29-22.9$ \\
rs4149056 (T/T) & 0.115 & - & - \\
rs4149056 (C/C) & 0.999 & - & - \\
rs4149056 (C/T) & 0.038 & 0.22 & $0.05-0.92$ \\
Goserelin therapy (no vs. yes) & 0.17 & 0.49 & $0.18-1.35$ \\
\hline
\end{tabular}


as expected, women who experienced CIA were significantly older than those who did not $(P=0.009)$. The risk of CIA in young patients with breast cancer ( $\leq 47$ years) does not appear to be related to BRCA1 or BRCA2 mutation status [35]. Again, age at treatment and use of tamoxifen were important predictors of CIA in women who carry a BRCA1 or BRCA2 mutation.

The major limitations of the study are the limited case number $(n=50)$ leading to a reduced statistical power of $70 \%$, and the inclusion of patients with goserelin treatment. Previous studies have suggested that temporary ovarian suppression with a GnRH analogue may preserve ovarian function both in humans and animal models [36]. However, the clinical data are conflicting. For example, the ZORO study randomised 60 ERnegative patients with breast cancer to anthracyclineand taxane-based chemotherapy alone or in combination with goserelin and found that there was no statistical difference in the resumption of ovarian function between the two groups [24]. This finding is confirmed in recent publications of other prospective trials [37, 38]. Currently, following publication of the Prevention of Early Menopause Study (POEMS) results [39, 40], the use of $\mathrm{GnRH}$ agonists during adjuvant chemotherapy outside clinical trials is being re-evaluated. Our data showed a trend for preservation of menstrual bleeding in patients receiving goserelin treatment concurrently with chemotherapy, but the difference was not statistically significant (Table 2). Administration of goserelin sequentially to chemotherapy as endocrine therapy in ER-positive disease had no impact on the occurrence of CIA.

Other methodologic concerns include inconsistencies in defining CIA and variability in the use of chemotherapeutic agents and tamoxifen in heterogeneous study population, depending on hormone-receptor status. However, our data do not support the hypothesis or previous findings that taxane-based chemotherapy or tamoxifen may have an impact on CIA (Table 2). For example, Najafi et al. [41] have reported that the type of chemotherapy is an important risk factor for CIA and that taxane-based regimens induced more CIA than other regimens. Non-cyclophosphamide treated controls or breast cancer patients without chemotherapy were not included in our study.

The lack of a consistent definition across breast cancer literature complicates incidence comparisons between different regimens and studies. The definition of CIA ranges from one missed period within 1 year to continuous cessation of menses for more than 1 year [3]. In summary, irreversible amenorrhea lasting for several $(>12)$ months following chemotherapy and an FSH level of $\geq 30 \mathrm{IU} / \mathrm{L}$ in the presence of a negative pregnancy test seems to be an appropriate characterization of chemotherapy-induced ovarian failure [42]. We used strict criteria to define CIA as no resumption of menstrual bleeding within 12 months after completion of chemotherapy or goserelin. However, cessation of menses is not synonymous with true ovarian failure because estrogen levels can remain in the premenopausal range even where CIA persists for 1 year or longer (as in $10 \%$ of our cases with CIA).

\section{Conclusions}

This pharmacogenomics study revealed a genetic effect on CIA in Caucasian women with early breast cancer receiving standard contemporary chemotherapy. The impact on CIA is due to genotype distribution of the SLC drug transporter gene SLCO1B1*5. A prospective validation of this finding is required in a larger cohort of premenopausal women using clearly predefined inclusion criteria (e.g., no treatment with goserelin). These data illustrate the potential power for predicting CIA based on a more profound understanding of inherited genetic factors.

\section{Additional files}

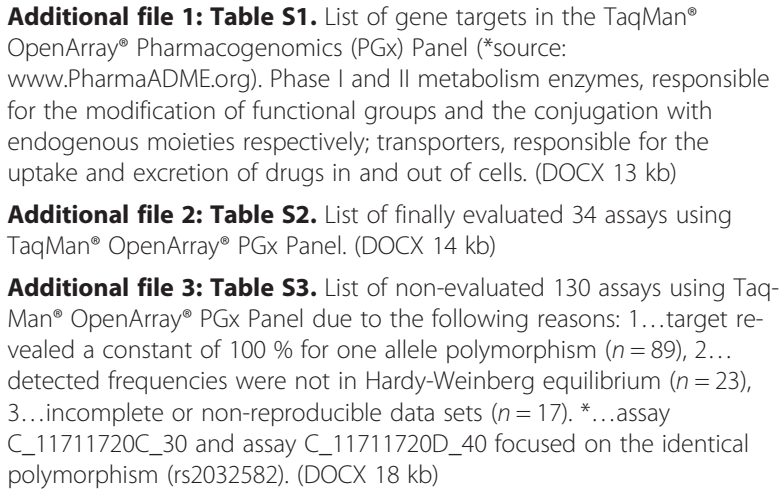

Additional file 1: Table S1. List of gene targets in the TaqMan ${ }^{\oplus}$ OpenArray ${ }^{\oplus}$ Pharmacogenomics (PGX) Panel ( ${ }^{*}$ source: www.PharmaADME.org). Phase I and II metabolism enzymes, responsible for the modification of functional groups and the conjugation with endogenous moieties respectively; transporters, responsible for the uptake and excretion of drugs in and out of cells. (DOCX 13 kb)

Additional file 2: Table S2. List of finally evaluated 34 assays using TaqMan $^{\oplus}$ OpenArray ${ }^{\oplus}$ PGx Panel. (DOCX 14 kb)

Additional file 3: Table S3. List of non-evaluated 130 assays using TaqMan $^{\circledast}$ OpenArray ${ }^{\circledast}$ PGx Panel due to the following reasons: 1 ...target revealed a constant of $100 \%$ for one allele polymorphism $(n=89), 2 \ldots$ detected frequencies were not in Hardy-Weinberg equilibrium $(n=23)$, 3... incomplete or non-reproducible data sets $(n=17)$. * . . assay C_11711720C_30 and assay C_11711720D_40 focused on the identical polymorphism (rs2032582). (DOCX 18 kb)

Additional file 4: Table S4. List of 33 computed, non-significant assays of interest with respect to menstrual bleeding after end of chemotherapy. (DOCX $21 \mathrm{~kb})$

\section{Acknowledgements}

We would like to thank David G. Beattie, M. Phil., for critical reading of the manuscript.

Funding

University of Rostock (FORUN 889030).

\section{Availability of data and materials}

The raw data will not be shared, because the used software platform (BioTrove Inc., Woburn, MA, USA) is not further supported since 2015. All potential findings based on row data analysis are presented in the manuscript or additional files.

\section{Authors' contributions}

TR participated in the design of the study, performed the statistical analysis and drafted the manuscript. SK carried out the molecular genetic analyses. BG and HT conceived the study, and participated in its design and coordination and helped to draft the manuscript. SH was involved in acquisition of patients and coordination of the database. DK carried out molecular genetic studies and performed the statistical analysis. All authors read and approved the final manuscript. 


\section{Consent for publication}

Not applicable.

\section{Ethics approval and consent to participate}

The study was conducted in the Department of Obstetrics and Gynecology, University of Rostock, and was approved by the Institutional Review Board (reference number A26-2008). All patients gave their informed consent prior to blood sampling.

\section{Author details}

'Department of Obstetrics and Gynecology, University of Rostock, Klinikum Suedstadt, Suedring 81, Rostock 18059, Germany. ${ }^{2}$ Institute of Immunology, University of Rostock, P.O.B. 100888, Rostock 18055, Germany.

Received: 1 February 2016 Accepted: 19 May 2016

Published online: 27 May 2016

\section{References}

1. Cancer in Germany 2007/2008. $8^{\text {th }}$ edition. Robert-Koch Institute (ed.) and the Association of Population-based Cancer Registries in Germany (ed.), Berlin, 2012

2. Early Breast Cancer Trialists' Collaborative Group. Effects of chemotherapy and hormonal therapy for early breast cancer on recurrence and 15-year survival: an overview of the randomised trials. Lancet. 2005;365:1687-717.

3. Walshe JM, Denduluri N, Swain SM. Amenorrhea in premenopausal women after adjuvant chemotherapy for breast cancer. J Clin Oncol. 2006;24:5769-79.

4. Swain SM, Jeong JH, Geyer Jr CE, Costantino JP, Pajon ER, Fehrenbacher $L$, et al. Longer therapy, iatrogenic amenorrhea, and survival in early breast cancer. N Engl J Med. 2010;362:2053-65.

5. Swain $\mathrm{SM}$, Jeong JH, Wolmark N. Amenorrhea from breast cancer therapy not a matter of dose. N Engl J Med. 2010;363:2268-70.

6. Schover LR. Premature ovarian failure and its consequences: vasomotor symptoms, sexuality, and fertility. J Clin Oncol. 2008;26:753-8.

7. Yoo C, Yun MR, Ahn JH, Jung KH, Kim HJ, Kim JE, et al. Chemotherapyinduced amenorrhea, menopause-specific quality of life, and endocrine profiles in premenopausal women with breast cancer who received adjuvant anthracycline-based chemotherapy: a prospective cohort study. Cancer Chemother Pharmacol. 2013;72:565-75.

8. Abusief ME, Missmer SA, Ginsburg ES, Weeks JC, Partridge AH. Relationship between reproductive history, anthropometrics, lifestyle factors, and the likelihood of persistent chemotherapy-related amenorrhea in women with premenopausal breast cancer. Fertil Steril. 2012;97:154-9.

9. Anderson RA, Rosendahl M, Kelsey TW, Cameron DA. Pretreatment antiMüllerian hormone predicts for loss of ovarian function after chemotherapy for early breast cancer. Eur J Cancer. 2013;49:3404-11.

10. Bozza C, Puglisi F, Lambertini M, Osa EO, Manno M, Del Mastro L. AntiMüllerian hormone: determination of ovarian reserve in early breast cancer patients. Endocr Relat Cancer. 2014;21:R51-65.

11. Perry JR, Day F, Elks CE, Sulem P, Thompson DJ, Ferreira T, et al. Parent-oforigin-specific allelic associations among 106 genomic loci for age at menarche. Nature. 2014;514:92-7.

12. De Bruin JP, Bovenhuis $H$, van Noord PAH, Pearson PL, van Arendonk JAM, te Velde ER, et al. The role of genetic factors in age at natural menopause. Hum Reprod. 2001;16:2014-8.

13. Stearns V, Schneider B, Henry L, Hayes DF, Flockhart DA. Breast cancer treatment and ovarian failure: risk factors and emerging genetic determinants. Nat Rev Cancer. 2006;6:886-93.

14. Colvin M, Padgett CA, Fenselau C. A biologically active metabolite of cyclophosphamide. Cancer Res. 1973;33:915-8.

15. Ngamjanyaporn $P$, Thakkinstian A, Verasertniyom $O$, Chatchaipun $P$, Vanichapuntu M, Nantiruj K, et al. Pharmacogenetics of cyclophosphamide and CYP2C19 polymorphism in Thai systemic lupus erythematosus. Rheumatol Int. 2011:31:1215-8.

16. Singh G, Saxena N, Aggarwal A, Misra R. Cytochrome P450 polymorphism as a predictor of ovarian toxicity to pulse cyclophosphamide in systemic lupus erythematosus. J Rheumatol. 2007; 34:731-3.

17. Takada K, Arefayene M, Desta Z, Yarboro CH, Boumpas DT, Balow JE, et al. Cytochrome P450 pharmacogenetics as a predictor of toxicity and clinical response to pulse cyclophosphamide in lupus nephritis. Arthritis Rheum. 2004;50:2202-10.
18. Su HI, Sammel MD, Velders L, Horn M, Stankiewicz C, Matro J, et al. Association of cyclophosphamide drug-metabolizing enzyme polymorphisms and chemotherapy-related ovarian failure in breast cancer survivors. Fertil Steril. 2010;94:645-54.

19. Wessels AM, Flockhart DA, Carpenter JS, Radovich M, Li L, Miller KD, et al. Cytochrome P450 polymorphisms and their relationship with premature ovarian failure in premenopausal women with breast cancer receiving doxorubicin and cyclophosphamide. Breast J. 2011;17:536-8.

20. Joyce H, McCann A, Clynes M, Larkin A. Influence of multidrug resistence and drug transport proteins on chemotherapy drug metabolism. Expert Opin Drug Metab Toxicol. 2015;11:795-809.

21. Liu T, Li Q. Organic anion-transporting polypeptides: a novel approach for cancer therapy. J Drug Target. 2014;22:14-22.

22. König J, Seithel A, Gradhand U, Fromm MF. Pharmacogenomics of human OATP transporters. Naunyn-Schmiedeberg's Arch Pharmacol. 2006;372:432-43.

23. Niemi M, Pasanen MK, Neuvonen PJ. Organic anion transporting polypeptide 1B1: a genetically polymorphic transporter of major importance for hepatic drug uptake. Pharmacol Rev. 2011;63:157-81.

24. Gerber B, von Minckwitz G, Stehle H, Reimer T, Felberbaum R, Maass N, et al. Effect of luteinizing hormone-releasing hormone agonist on ovarian function after modern adjuvant breast cancer chemotherapy: the GBG 37 ZORO study. J Clin Oncol. 2011;29:2334-41.

25. Faul F, Erdfelder E, Buchner A, Lang AG. Statistical power analyses using G*Power 3.1: tests for correlation and regression analyses. Behav Res Methods. 2009:41:1149-60.

26. Evans WE, McLeod HL. Pharmacogenomics - drug disposition, drug targets, and side effects. N Engl J Med. 2003;348:538-49.

27. Wang L, McLoad HL, Weinshilboum RM. Genomics and drug response. N Engl J Med. 2011;364:1144-53.

28. SEARCH Collaborative Group, Link E, Parish S, Armitage J, Heath S, Matsuda F, Gut I, et al. SLCO1B1 variants and statin-induced myopathy - a genomewide study. N Engl J Med. 2008;359:789-99.

29. Abe T, Kakyo M, Tokui T, Nakagomi R, Nishio T, Nakai D, et al. Identification of a novel gene family encoding human liver-specific organic anion transporter LST-1. J Biol Chem. 1999;274:17159-63.

30. Treviño LR, Shimasaki N, Yang W, Panetta JC, Cheng C, Pei D, et al. Germline genetic variation in an organic anion transporter polypeptide associated with methotrexate pharmacokinetics and clinical effects. J Clin Oncol. 2009; 27:5972-8.

31. van der Deure WM, Friesema EC, de Jong FJ, de Rijke YB, de Jong FH, Uitterlinden AG, et al. Organic anion transporter 1B1: an important factor in hepatic thyroid hormone and estrogen transport and metabolism. Endocrinology. 2008;149:4695-701.

32. Lee E, Schumacher F, Lewinger JP, Neuhausen SL, Anton-Culver H, Horn-Ross PL, et al. The association of polymorphisms in hormone metabolic pathway genes, menopausal hormone therapy, and breast cancer risk: a nested case-control study in the California teachers study cohort. Breast Cancer Res. 2011;13:R37.

33. Nigam SK. What do drug transporters really do? Nat Rev Drug Discov. 2015; 14:29-44.

34. Lee S, Kil WJ, Chun M, Kang SY, Kang SH, Oh YT. Chemotherapy-related amenorrhea in premenopausal women with breast cancer. Menopause. 2009;16:98-103.

35. Valentini A, Finch A, Lubinski J, Byrski T, Ghadirian P, Kim-Sing C, et al. Chemotherapy-induced amenorrhea in patients with breast cancer with a BRCA1 or BRCA2 mutation. J Clin Oncol. 2013;31:3914-9.

36. Wong M, O'Neill S, Walsh G, Smith IE. Goserelin with chemotherapy to preserve ovarian function in pre-menopausal women with early breast cancer: menstruation and pregnancy outcomes. Ann Oncol. 2013;24:133-8.

37. Munster P, Moore AP, Ismail-Khan R, Cox CE, Lacevic M, Gross-King M, et al. Randomized trial using gonadotropin-releasing hormone agonists triptorelin for the preservation of varian function during (neo)adjuvant chemotherapy for breast cancer. J Clin Oncol. 2012;30:533-8.

38. Elgindy EA, El-Haieg DO, Khorshid OM, Ismail El, Abdelgawad M, Sallam HN, et al. Gonadotrophin suppression to prevent chemotherapy-induced ovarian damage: a randomized controlled trial. Obstet Gynecol. 2013;121:78-86.

39. Turner NH, Partridge A, Sanna G, Di Leo A, Biganzoli L. Utility of gonadotropin-releasing hormone agonists for fertility preservation in young breast cancer patients: the benefit remains uncertain. Ann Oncol. 2013;24: 2224-35. 
40. Moore HCF, Unger JM, Philipps KA, Boyle F, Hitre E, Porter D, et al. Goserelin for ovarian protection during breast-cancer adjuvant chemotherapy. N Engl J Med. 2015;372:923-32.

41. Najafi S, Djavid GE, Mehrdad N, Rajaii E, Alavi N, Olfatbakhsh A, et al. Taxanebased regimens as a risk factor for chemotherapy-induced amenorrhea. Menopause. 2011;18:208-12.

42. Molina JR, Barton DL, Loprinzi CL. Chemotherapy-induced ovarian failure: manifestations and management. Drug Saf. 2005;28:401-16.

Submit your next manuscript to BioMed Central and we will help you at every step:

- We accept pre-submission inquiries

- Our selector tool helps you to find the most relevant journal

- We provide round the clock customer support

- Convenient online submission

- Thorough peer review

- Inclusion in PubMed and all major indexing services

- Maximum visibility for your research

Submit your manuscript at www.biomedcentral.com/submit 